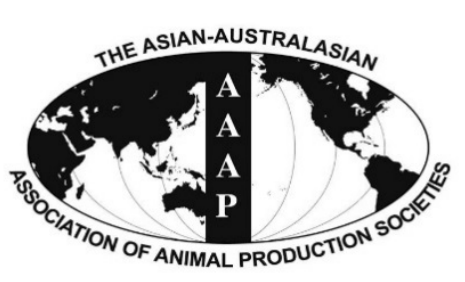

Open Access

\begin{tabular}{c} 
Open Access \\
$\begin{array}{c}\text { Asian Australas. J. Anim. Sci. } \\
\text { Vol. 29, No. 6 : 901-907 June } 2016 \\
\text { http://dx.doi.org/10.5713/ajas.15.0456 }\end{array}$ \\
\hline www.ajas.info \\
pISSN 101 1-2367 elSSN 1976-5517
\end{tabular}

\title{
Factors Affecting the Incidence of Angel Wing in White Roman Geese: Stocking Density and Genetic Selection
}

\author{
M. J. Lin',2, S. C. Chang',2, T. Y. Lin'², Y. S. Cheng ${ }^{3}$, Y. P. Lee', and Y. K. Fan',* \\ ${ }^{1}$ Department of Animal Science, National Chung Hsing University, Taichung 40227, Taiwan
}

\begin{abstract}
The present study investigated stocking density and genetic lines, factors that may alter the severity and incidence of angel wing $(\mathrm{AW})$, in White Roman geese. Geese $(\mathrm{n}=384)$ from two genetically selected lines (normal- winged line, NL, and angelwinged line, AL, respectively) and one commercial line (CL) were raised in four pens. Following common commercial practice, lowstocking-density (LD), medium-stocking-density, and high-stocking-density treatments were respectively administered to 24,32 , and 40 geese per pen at 0 to 3 weeks $\left(1.92 \mathrm{~m}^{2} /\right.$ pen) and 4 to 6 weeks $\left(13.2 \mathrm{~m}^{2} /\right.$ pen) of age and to 24,30 , and 36 geese at 7 to 14 weeks $(20.0$ $\mathrm{m}^{2} /$ pen) of age. The results revealed that stocking density mainly affected body weight gain in geese younger than 4 weeks, and that geese subjected to LD had a high body weight at 2 weeks of age. However, the effect of stocking density on the severity score of AW (SSAW) and incidence of AW (IAW) did not differ significantly among the treatments. Differences were observed among the genetic stocks; that is, SSAW and IAW were significantly higher in AL than in NL and CL. Genetic selection generally aggravates AW, complicating its elimination. To effectively reduce IAW, stocking density, a suspected causal factor, should be lower than that presently applied commercially. (Key Words: Angel Wing, Stocking Density, Genetics, White Roman Geese)
\end{abstract}

\section{INTRODUCTION}

Angel wing (AW) occurs on either or both wings of birds and affects the carpometacarpus or the joint between the third and fourth metacarpals that twists outward away from body mostly during growth, resulting in wings resembling those of an angel (Grow, 1972; Mildred and Holderread, 1981). AW occurs in various species, including swan goose, giant Canada goose, Hawaiian goose, Andean goose, Magellan goose, blue-winged goose, Egyptian goose, Indian spotbill, Puna teal, New Zealand gray duck, African yellow-billed duck, chestnut-breasted teal, crested duck, red-crested pochard, rosybill, mountain duck, and wild-type Muscovy (Kear, 1973). Moreover, the inability of wild

\footnotetext{
* Corresponding Author: Y. K. Fan. Tel: +886-4-22853748, Fax: +886-4-22860265, E-mail: ykfan@dragon.nchu.edu.tw

2 Changhua Animal Propagation Station, Livestock Research Institute, Council of Agriculture, Executive Yuan, Changhua 52149, Taiwan.

${ }^{3}$ Livestock Research Institute, Council of Agriculture, Executive Yuan, Tainan 71246, Taiwan.

Submitted May 24, 2015; Revised Jul. 6, 2015; Accepted Aug. 2, 2015
}

waterfowls to fly substantially posed threat to their lives and conservation. Domestic geese can also be affected by AW (Francis et al., 1967); nevertheless, their production efficiency is unaffected.

Few studies have reported the incidence of AW (IAW). Francis et al. (1967) indicated that AW in White Chinese geese was mainly due to hereditary factors; however, most studies on wild waterfowl have revealed that environmental factors are more crucial. Kear (1973) reported that inappropriate nutrition, high-protein diet, and lack of exercise were the main causes of AW in wild waterfowl. Kreeger and Walser (1984) hypothesized that AW in giant Canada geese occurs because of their rapidly growing flight feathers, with the consequent weight gain exceeding the muscular stabilization of the carpal joints; eventually, gravity pulls the wing tip outward. AW also occurs in rapidly growing birds, such as domestic and wild waterfowl fed by humans. IAW is associated with overfeeding; an unbalanced diet, including excessive protein intake; and calcium, manganese, and vitamin D deficiency (Kuiken et al., 1999). However, these results were based only on the observation of wild birds. Thus far, no rigorous experiments 
have been conducted for elucidating the mechanism of AW.

Geese rearing is a vital farming activity in Taiwan, and White Roman geese account for approximately $97.6 \%$ of the market share (Wang et al., 1996). An on-farm investigation revealed a $5 \%$ to $50 \%$ IAW in a flock (Lee, 2004 ). If AW is observed in $>30 \%$ of the birds in a flock, the entire flock is commercially rejected in Taiwan.

Considering the aforementioned factors, we performed a series of experiments investigating factors such as etiology, stocking density, dietary mycotoxin effects, dietary nutrition concentration, and heredity, which may be associated with IAW in White Roman geese. In this study, we examined the effect of stocking density, which possibly causes, triggers, or prevents IAW, in three genetic lines of White Roman geese.

\section{MATERIALS AND METHODS}

\section{Birds and management}

All geese were reared and maintained according to the Regulations of Laboratory Animals, Changhua Animal Propagation Station, Livestock Research Institute (CAPSLRI, $23^{\circ} 51^{\prime} \mathrm{N}$ and $120^{\circ} 33^{\prime} \mathrm{E}$ ), Council of Agriculture, Taiwan. Normal lines and AW lines (hereafter, NL and AL, respectively) originating from the same lineage of highbody-weight geese (Lin et al., 2010) were established at
CAPS-LRI in 2008 by divergent selection for normal wings (NWs) and AWs, judged by the appearance at 14 weeks of age. Geese obtained from a commercial farm comprised the commercial line $(\mathrm{CL})$.

Day-old goslings were placed in the primary house with a cemented floor after vent sexing and foot band aging. The goslings were moved to the growing house at 3 weeks of age and relocated at 6 weeks to another growing house with a pool.

The geese were fed commercial rations containing $20 \%$ crude protein (CP) in addition to 2,900 $\mathrm{kcal} / \mathrm{kg}$ metabolizable energy (ME) and $15 \% \mathrm{CP}$ in addition to 2,800 kcal/kg ME (Table 1) during 0 to 4 (brooding stage) and 5 to 14 weeks (growing stage) of age, respectively. At 0 to 14 weeks of age, the geese were fed dietary CP according to the concentration recommended by the National Research Council (NRC, 1994). The dietary ME content fed to the geese in the brooding stage was also in conformance with NRC recommendations (1994). However, the dietary $\mathrm{ME}$ content fed to the geese in the growing stage was lower than that recommended $(3,000 \mathrm{kcal} / \mathrm{kg})$ by the $\mathrm{NRC}$, following the commendations of studies pertaining to and conducted under the high ambient temperature and humidity in Taiwan.

The goose house was cleaned two times weekly. Mashed diets and drinking water were provided ad libitum.

Table 1. Components and compositions of the experimental diets

\begin{tabular}{|c|c|c|}
\hline \multirow{2}{*}{ Item } & \multicolumn{2}{|c|}{ Experimental diet } \\
\hline & Starter (0 to 4 week) & Grower (5 to 14 week) \\
\hline \multicolumn{3}{|l|}{ Ingredients $(\mathrm{g} / \mathrm{kg})$} \\
\hline Yellow corn & 614 & 642.5 \\
\hline Soybean meal, $44 \%$ & 260 & 215 \\
\hline Wheat bran & 20 & 50 \\
\hline Fish meal, $65 \%$ crude protein & 50 & \\
\hline Molasses & 30 & 30 \\
\hline Salt & 3 & 3 \\
\hline Dicalcium phosphate, $22 \%$ phosphorous & 10 & 16 \\
\hline Limestone, pulverized & 7 & 8 \\
\hline Choline chloride, $50 \%$ & 1 & 1 \\
\hline DL-methionine & 2.5 & 2 \\
\hline Rice bran & - & 30 \\
\hline Vitamin premix $^{1}$ & 1 & 1 \\
\hline Mineral premix ${ }^{2}$ & 1.5 & 1.5 \\
\hline \multicolumn{3}{|l|}{ Calculated values } \\
\hline Crude protein $(\%)$ & 20 & 15 \\
\hline Metabolizable energy (kcal/kg) & 2,900 & 2,800 \\
\hline \multicolumn{3}{|l|}{ Analyzed values } \\
\hline Crude protein $(\%)$ & $19.8 \pm 0.11(\mathrm{~N}=3)$ & $14.8 \pm 0.13(\mathrm{~N}=3)$ \\
\hline Gross energy (kcal/kg) & $3,880 \pm 74.7(\mathrm{~N}=3)$ & $3,621 \pm 22.8(\mathrm{~N}=3)$ \\
\hline
\end{tabular}


During 0 to 3 weeks of age, light and heat were supplied all day by using a $60-\mathrm{W}$ incandescent bulb, and the highest and lowest ambient temperatures of the nursery house were $31.2^{\circ} \mathrm{C} \pm 1.62^{\circ} \mathrm{C}$ and $27.2^{\circ} \mathrm{C} \pm 1.03^{\circ} \mathrm{C}$, respectively. Subsequently, the birds were exposed to natural light, and the average ambient temperature was $26.4^{\circ} \mathrm{C} \pm 4.05^{\circ} \mathrm{C}$.

\section{Experimental design}

Twelve pens were randomly assigned to low, medium, and high stocking density (hereafter, LD, MD, and HD, respectively), and each pen included the genetic lines NL, $\mathrm{AL}$, and CL.

$\mathrm{LD}, \mathrm{MD}$, and HD treatments were administered to 24 , 32 , and 40 geese in a wire-floor pen of area $1.92 \mathrm{~m}^{2}(12.5$, 16.7 , and $20.8 \mathrm{~kg}$ body weight $/ \mathrm{m}^{2}$ ) from hatching to 3 weeks of age, in a cemented floor pen of area $13.2 \mathrm{~m}^{2}(4.64$, 6.18 , and $7.73 \mathrm{~kg}$ body weight $/ \mathrm{m}^{2}$ ) from 4 to 6 weeks of age, and in a cemented floor pen of area $20.0 \mathrm{~m}^{2}(5.75,7.18$, and $8.62 \mathrm{~kg}$ body weight $/ \mathrm{m}^{2}$ ) from 7 to 14 weeks of age. In total, 384 geese $(90,69$, and $225 \mathrm{AL}, \mathrm{NL}$, and CL geese, respectively) were included. Each pen comprised 7 to 8 geese with NWs and 6 to 7 geese with AWs; the rest were CL geese included to balance the number of males and females.

\section{Growth performance}

The body weight and weight gain of the geese were

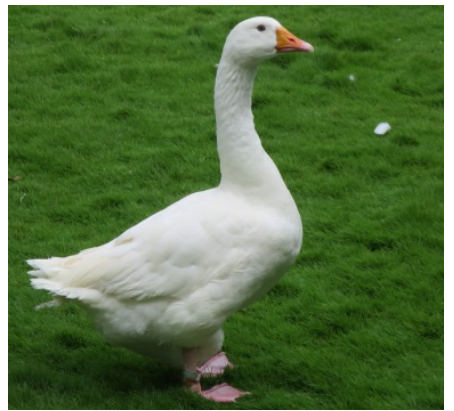

(a) Normal wing

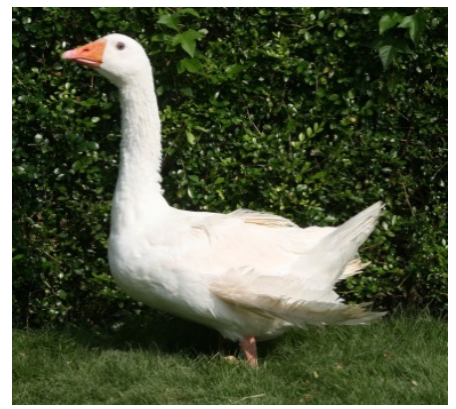

(c) Medium angel wing measured biweekly and individually. Feed consumption was recorded on a pen basis up to 14 weeks of age, and feed conversion ratios were accordingly calculated.

\section{Severity score and incidence of angel wing}

Field observations in Taiwan show that goslings generally start molting feathers at 2 weeks of age, and their primary feathers completely grow by 5 to 6 weeks of age. Furthermore, AW in geese occurs at 6 weeks of age; no AW occurs after 13 to 14 weeks of age.

Therefore, the severity score of AW (SSAW) and IAW of geese were recorded biweekly and individually at 6 to 14 weeks of age. A wing was judged to be AW if the end of the primary feather did not closely and smoothly fit into its body. AWs were visually categorized as slight, medium, and severe according to the degree of projection of the primary feathers away from the body $\left(\left[<30^{\circ}, 30^{\circ}\right.\right.$ to $60^{\circ}$, and $>60^{\circ}$ and Figures $1 \mathrm{~b}$ to $1 \mathrm{~d}$ ], respectively). The slight, medium, and severe AWs were scored 1, 2, and 3, respectively, and the sum score of a pair of wings, ranging from 0 to 6 , was defined as the SSAW of a goose. A score of 0 indicated NW (Figure 1a) and 6 indicated severe AW in both wings (Figure 1d). The IAW of a flock was defined as the proportion of geese with AW.

\section{Statistical analyses}

Growth performance and SSAW were statistically

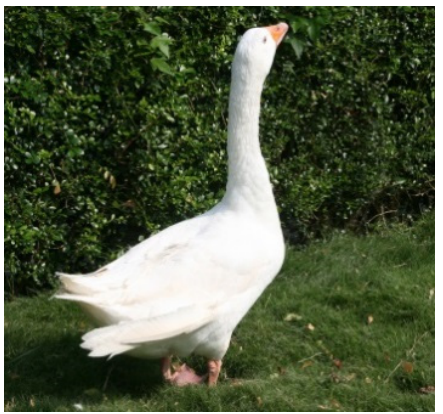

(b) Slight angel wing

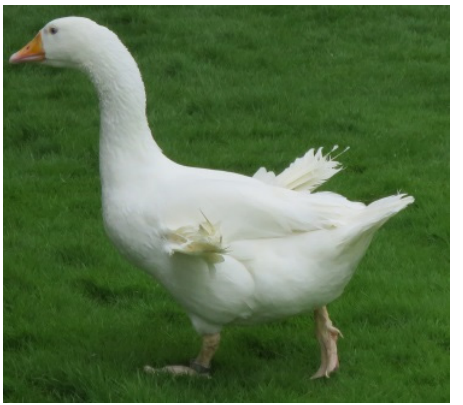

(d) Severe angel wing

Figure 1. Appearances of a normal wing and the severity of angel wing in White Roman goose. (a) A normal bird wing is covered with smooth, neat, and clean feathers that fit neatly along its body. Angel wings with the primary feathers projecting away from the body at an angle of $<30^{\circ}, 30^{\circ}$ to $60^{\circ}$, and $>60^{\circ}$ were categorized as (b) slight, (c) medium, and (d) severe, and scored 1,2 , and 3, respectively. The severity score of a pair of angel wings ranged from 0 (normal wings [a]) to 6 (two severe angel wings [d]). These definitions are from Lin et al. (2012). 
analyzed using the general linear model procedure of SAS (2004), and the mean AW and NW of geese were compared by using the LSMEANS statement. The significances of IAW among the three stocking densities and genetic lines were tested using the chi-square test and the frequency procedure of SAS.

\section{RESULTS}

\section{Growth performance}

The effects of stocking density and genetic lines on body weight and weight gain are shown in Table 2 . The body weight of geese subjected to LD was higher because of the weight gain at 4 weeks of age. By contrast, body weight gain was higher for AL and NL geese at 6 weeks of age, resulting in higher body weights than that of CL geese at $\geq 8$ weeks of age. No significant interaction effects of stocking densities with genetic lines were observed on body weight gain.

The average feed consumption for the three stocking densities are detailed in Table 3. Geese subjected to HD had less feed consumption at $\leq 8$ weeks of age. However, no significant differences were observed in the feed conversion ratio among the three stocking densities during the growth stage.

\section{Severity score of angel wing and incidence of angel wing}

The effects of stocking density and genetic line on SSAW and IAW in White Roman geese during 6 to 14 weeks of age are shown in Table 4. Geese subjected to LD reported a lower IAW at 6 weeks of age; however, no
Table 3. Effect of stocking density on feed consumption and the conversion ratio in 0 to 14 -week-old White Roman geese

\begin{tabular}{lccccc}
\hline \multirow{2}{*}{ Age } & \multicolumn{3}{c}{ Stocking density } & \multirow{2}{*}{ SEM } & \multirow{2}{*}{ Significance $^{1}$} \\
\cline { 2 - 4 } & LD & MD & HD & & \\
\hline Feed consumption (kg/bird) & & & \\
0 to 4 wk & $2.93^{\mathrm{a}}$ & $2.47^{\mathrm{b}}$ & $2.05^{\mathrm{c}}$ & 0.06 & $* * *$ \\
5 to $8 \mathrm{wk}$ & $9.59^{\mathrm{a}}$ & $8.68^{\mathrm{b}}$ & $8.15^{\mathrm{b}}$ & 0.17 & $* *$ \\
9 to $14 \mathrm{wk}$ & 11.3 & 11.1 & 10.5 & 0.15 & $\mathrm{NS}$ \\
0 to $14 \mathrm{wk}$ & $23.8^{\mathrm{a}}$ & $22.2^{\mathrm{b}}$ & $20.7^{\mathrm{c}}$ & 0.14 & $* * *$ \\
Feed conversion ratio & & & & \\
(kg feed/kg body weight gain) & & & \\
0 to $4 \mathrm{wk}$ & 2.03 & 2.04 & 1.95 & 0.02 & $\dagger$ \\
5 to $8 \mathrm{wk}$ & 3.97 & 3.77 & 3.66 & 0.13 & $\mathrm{NS}$ \\
9 to $14 \mathrm{wk}$ & 10.0 & 9.09 & 9.17 & 0.27 & $\mathrm{NS}$ \\
0 to $14 \mathrm{wk}$ & 4.77 & 4.70 & 4.65 & 0.06 & $\mathrm{NS}$ \\
\hline
\end{tabular}

LD, low stocking density; MD, medium stocking density; HD, high stocking density; SEM, standard error of means.

NS, nonsignificantly different or $\mathrm{p}>0.1 ; \uparrow \mathrm{p}<0.1$. ${ }^{* *} \mathrm{p}<0.01 ; * * \mathrm{p}<0.001$. a,b,c Entries in the same row with different superscripts differ significantly $(\mathrm{p}<0.05)$.

significant differences were observed in SSAW and IAW among the three stocking densities from 8 to 14 weeks of age. Compared with CL and NL, AL, a line genetically selected for a high IAW, had a higher SSAW and IAW at $\geq 8$ weeks of age $(p<0.001)$. In $A L, N L$, and $C L$, IAW, and SSAW, measured at 14 weeks of age when AWs were morphologically visible, were $69.5 \%, 32.5 \%$, and $32.6 \%$ and $2.54,0.98$, and 0.90 , respectively. The stocking density and genetic lines revealed no significant interaction effects on SSAW and IAW.

Table 2. Effects of stocking density and genetic lineage on body weight and weight gain in 0 to 14-week-old White Roman geese

\begin{tabular}{|c|c|c|c|c|c|c|c|c|c|c|c|}
\hline \multirow{2}{*}{ Age } & \multicolumn{3}{|c|}{ Stocking density } & \multirow{2}{*}{$\mathrm{SEM}^{1}$} & \multicolumn{3}{|c|}{ Line } & \multirow{2}{*}{$\mathrm{SEM}^{2}$} & \multicolumn{3}{|c|}{ Significance $^{3}$} \\
\hline & LD & MD & HD & & $\mathrm{AL}$ & NL & $\mathrm{CL}$ & & $\mathrm{D}$ & $\mathrm{L}$ & $\mathrm{D} \times \mathrm{L}$ \\
\hline \multicolumn{12}{|c|}{ Body weight (kg/bird) } \\
\hline $0 \mathrm{wk}$ & 0.105 & 0.102 & 0.103 & 0.001 & 0.107 & 0.104 & 0.099 & 0.001 & NS & NS & NS \\
\hline $2 \mathrm{wk}$ & $0.689^{\mathrm{a}}$ & $0.611^{\mathrm{b}}$ & $0.558^{\mathrm{b}}$ & 0.02 & 0.599 & 0.584 & 0.642 & 0.01 & $* *$ & NS & NS \\
\hline $4 \mathrm{wk}$ & $1.55^{\mathrm{a}}$ & $1.31^{\mathrm{b}}$ & $1.15^{\mathrm{c}}$ & 0.04 & 1.36 & 1.33 & 1.34 & 0.03 & $* *$ & NS & NS \\
\hline $6 \mathrm{wk}$ & $2.87^{\mathrm{a}}$ & $2.51^{\mathrm{b}}$ & $2.38^{\mathrm{c}}$ & 0.03 & 2.59 & 2.64 & 2.55 & 0.03 & $* * *$ & NS & * \\
\hline $8 \mathrm{wk}$ & $3.97^{\mathrm{a}}$ & $3.62^{\mathrm{b}}$ & $3.41^{\mathrm{c}}$ & 0.03 & $3.75^{\mathrm{a}}$ & $3.78^{\mathrm{a}}$ & $3.57^{\mathrm{b}}$ & 0.04 & $* * *$ & $* *$ & NS \\
\hline $10 \mathrm{wk}$ & $4.66^{\mathrm{a}}$ & $4.42^{\mathrm{b}}$ & $4.17^{\mathrm{c}}$ & 0.04 & $4.52^{\mathrm{a}}$ & $4.59^{\mathrm{a}}$ & $4.29^{\mathrm{b}}$ & 0.04 & $* * *$ & $* * *$ & $\dagger$ \\
\hline $12 \mathrm{wk}$ & $4.96^{\mathrm{a}}$ & $4.72^{\mathrm{b}}$ & $4.38^{c}$ & 0.07 & $4.79^{a}$ & $4.90^{\mathrm{a}}$ & $4.56^{\mathrm{b}}$ & 0.06 & $* *$ & $* *$ & NS \\
\hline $14 \mathrm{wk}$ & $5.09^{\mathrm{a}}$ & $4.84^{\mathrm{b}}$ & $4.56^{\mathrm{c}}$ & 0.05 & $4.93^{\mathrm{b}}$ & $5.13^{\mathrm{a}}$ & $4.67^{\mathrm{c}}$ & 0.05 & $* * *$ & $* * *$ & NS \\
\hline \multicolumn{12}{|c|}{ Body weight gain (kg/bird) } \\
\hline 0 to $4 \mathrm{wk}$ & $1.44^{\mathrm{a}}$ & $1.21^{\mathrm{b}}$ & $1.05^{\mathrm{c}}$ & 0.04 & 1.25 & 1.22 & 1.24 & 0.03 & $* *$ & NS & NS \\
\hline 5 to $8 \mathrm{wk}$ & 2.42 & 2.30 & 2.24 & 0.06 & 2.37 & 2.42 & 2.23 & 0.05 & NS & NS & NS \\
\hline 9 to $14 \mathrm{wk}$ & 1.12 & 1.22 & 1.14 & 0.04 & $1.19^{\mathrm{b}}$ & $1.33^{\mathrm{a}}$ & $1.10^{\mathrm{b}}$ & 0.03 & NS & $* * *$ & NS \\
\hline 0 to $14 \mathrm{wk}$ & $4.98^{\mathrm{a}}$ & $4.74^{b}$ & $4.45^{\mathrm{c}}$ & 0.04 & $4.82^{\mathrm{a}}$ & $4.99^{\mathrm{a}}$ & $4.57^{\mathrm{b}}$ & 0.06 & $* * *$ & $* * *$ & NS \\
\hline
\end{tabular}

LD, low stocking density; MD, medium stocking density; HD, high stocking density; AL, angel wing line; NL, normal wing line; CL, commercial line; L, genetic line; D, stocking density; $\mathrm{L} \times \mathrm{D}$, the interaction of stocking density with genetic line.

${ }^{1}$ SEM, standard error of the mean of stocking densities. ${ }^{2}$ Standard error of the mean of genetic lines.

${ }^{3} \mathrm{NS}$, nonsignificantly different or $\mathrm{p}>0.1 . \dagger \mathrm{p}<0.1 ; * \mathrm{p}<0.05 ; * * \mathrm{p}<0.01 ; * * * \mathrm{p}<0.001$.

${ }^{a, b, c}$ Stocking densities and genetic lines with different superscripts differ significantly $(\mathrm{p}<0.05)$. 
Table 4. Effect of stocking density and genetic lineage on the severity score and incidence of angel wing in 6 to 14-week-old White Roman geese

\begin{tabular}{|c|c|c|c|c|c|c|c|c|c|c|c|}
\hline \multirow{2}{*}{ Age } & \multicolumn{3}{|c|}{ Stocking density } & \multirow{2}{*}{ SEM $^{1}$} & \multicolumn{3}{|c|}{ Line } & \multirow{2}{*}{ SEM $^{2}$} & \multicolumn{3}{|c|}{ Significance $^{3}$} \\
\hline & LD & MD & HD & & $\mathrm{AL}$ & NL & $\mathrm{CL}$ & & $\mathrm{D}$ & $\mathrm{L}$ & $\mathrm{D} \times \mathrm{L}$ \\
\hline \multicolumn{12}{|c|}{ Severity score of angel wing } \\
\hline $6 \mathrm{wk}$ & 0.34 & 0.63 & 0.50 & 0.14 & 1.07 & 0.44 & 0.28 & 0.16 & NS & NS & NS \\
\hline $8 \mathrm{wk}$ & 0.93 & 1.12 & 1.09 & 0.12 & $2.09^{\mathrm{a}}$ & $0.69^{\mathrm{b}}$ & $0.72^{\mathrm{b}}$ & 0.17 & NS & $* * *$ & NS \\
\hline $10 \mathrm{wk}$ & 0.92 & 1.23 & 0.98 & 0.14 & $2.16^{\mathrm{a}}$ & $0.84^{\mathrm{b}}$ & $0.62^{\mathrm{b}}$ & 0.19 & NS & $* * *$ & NS \\
\hline $12 \mathrm{wk}$ & 0.99 & 1.48 & 1.21 & 0.15 & $2.46^{\mathrm{a}}$ & $0.91^{\mathrm{b}}$ & $0.79^{\mathrm{b}}$ & 0.22 & NS & $* * *$ & NS \\
\hline $14 \mathrm{wk}$ & 1.16 & 1.49 & 1.28 & 0.22 & $2.54^{\mathrm{a}}$ & $0.98^{\mathrm{b}}$ & $0.90^{\mathrm{b}}$ & 0.25 & NS & $* * *$ & NS \\
\hline \multicolumn{12}{|c|}{ Incidence of angel wing $(\%)$} \\
\hline $6 \mathrm{wk}$ & 15.5 & 30.1 & 21.3 & 5.66 & 46.2 & 18.4 & 15.2 & 5.96 & NS & NS & NS \\
\hline $8 \mathrm{wk}$ & 37.5 & 45.8 & 42.1 & 3.58 & $69.8^{\mathrm{a}}$ & $29.8^{\mathrm{b}}$ & $32.7^{\mathrm{b}}$ & 4.28 & NS & $* * *$ & $\dagger$ \\
\hline $10 \mathrm{wk}$ & 34.4 & 47.5 & 36.5 & 6.64 & $69.5^{\mathrm{a}}$ & $31.0^{\mathrm{b}}$ & $27.7^{\mathrm{b}}$ & 5.38 & NS & $* * *$ & NS \\
\hline $12 \mathrm{wk}$ & 39.9 & 47.5 & 41.9 & 7.25 & $71.0^{\mathrm{a}}$ & $33.1^{\mathrm{b}}$ & $33.1^{\mathrm{b}}$ & 6.30 & NS & $* * *$ & NS \\
\hline $14 \mathrm{wk}$ & 39.9 & 46.7 & 39.4 & 5.91 & $69.5^{\mathrm{a}}$ & $32.5^{\mathrm{b}}$ & $32.6^{\mathrm{b}}$ & 5.87 & NS & $* * *$ & NS \\
\hline
\end{tabular}

LD, low stocking density; MD, middle stocking density; HD, high stocking density; AL, angel wing line; NL, normal wing line; CL, commercial line; L, genetic line; $\mathrm{D}$, stocking density; $\mathrm{L} \times \mathrm{D}$, the interaction of stocking density with genetic line.

${ }^{1} \mathrm{SEM}$, standard error of means of stocking densities. ${ }^{2}$ Standard error of means of genetic lines.

${ }^{3} \mathrm{NS}$, non significantly different or $\mathrm{p}>0.1 ; \dagger \mathrm{p}<0.1 ; * * \mathrm{p}<0.001$.

${ }^{\mathrm{a}, \mathrm{b}}$ Stocking densities and genetic lines with different superscripts differ significantly $(\mathrm{p}<0.05)$.

\section{DISCUSSION}

Kear (1973) reported that IAW in wild geese is affected by several factors, including; lack of exercise, large flock size, improper feeding, rearing under heat stress because of high ambient temperatures, feeling frightened frequently, and improper management.

Among all unfavorable factors, HD is observed most frequently. Commercial farms usually rear as many birds as possible in as little space as possible to reduce the fixed production cost. The amount of space that sustains favorable productivity is not necessarily sufficient for the exercise necessary for a normally developing wing and muscle strengthening. Stocking density may cause stressful social and physical environments, subsequently triggering IAW in geese and other birds. In Taiwan, a common practice is to rear 500 goslings in a $36 \mathrm{~m}^{2}$ pen during the brooding stage $\left(13.9 \mathrm{birds} / \mathrm{m}^{2}\right)$, gradually increasing the space to $1.2-1.5 \mathrm{birds} / \mathrm{m}^{2}$ as the geese grow. The stocking density in this experiment was 12.5 to $20.8,1.8$ to 3.0 , and 1.2 to $1.8 \mathrm{birds} / \mathrm{m}^{2}$ for 0 to 3,4 to 6 , and 7 to 14 -week-old birds, respectively.

The stocking density implemented in this study for geese from hatching to 3 weeks of age appeared to be ineffective, and the outcomes deteriorated with increasing stocking density. Furthermore, the body weight gain by 4 weeks of age (Table 2) was mostly attributable to the restriction of feed consumption by HD (Table 3). The effect of stocking density on IAW was not as clear as it was on body weight gain; however, LD significantly reduced IAW (Table 4). The effect of LD and that of the average of MD and HD on IAW at 6 weeks of age was non-significant $\left(15.4 \%\right.$ vs $\left.25.3 \% ; x^{2}=3.53, \mathrm{df}=2, \mathrm{p}>0.10\right)$. By contrast, compared with the average of MD and $\mathrm{HD}$, LD significantly influenced NL $\left(4.17 \%\right.$ vs $25.8 \%, x^{2}=5.57$, df $=2, \mathrm{p}<0.10)$. In this study, NL more sensitively responded to the stocking density than did AL, which probably required more space for avoiding AW. These results suggest that the stocking density required for triggering IAW varies among genetic lines. Additional related studies are required for elucidating the cause-effect of AW and stocking density.

No significant difference was observed in SSAW and IAW among the three stocking densities at 6 weeks of age (Table 4), suggesting that the HD applied in this study presented a satisfactory growth performance but not sufficient space for avoiding IAW. In rapidly growing poultry, bone development and maturity cannot keep pace with the overall growth, generating excess physical load and predisposing bones to deformity and fragility (Rath et al., 2000). Furthermore, the extremely high IAW observed in the LD group after 8 weeks of age suggests that geese require more space than was provided for exercising and stretching wings for normal growth and healthy wings.

According to our review of relevant literature, the genetics of AW in geese was first reported by Francis et al. (1967). They observed AW in 53\% of White Chinese goslings with AW parents, thus indicating that IAW in geese is attributable to polygenic determinism. Moreover, Lin et al. (2012) reported that the SSAW and IAW of White Roman goslings with AW at 8 weeks of age were $1.45 \%$ and $48.6 \%$, respectively, whereas those of commercial White Roman goslings at the same age were $0.40 \%$ and 
$14.8 \%$, respectively. These results revealed that parental and genetic factors play a substantial role in IAW and SSAW. Therefore, we conducted a divergent genetic selection for A Lin White Roman geese in Taiwan; the results will be published separately.

In this study, the SSAW and IAW results revealed that AW was more severe in AL than in NL. However, the IAW was higher in NL than in CL, implying that genetic selection effectively increases IAW and improves the production efficiency of domestic geese. The results also imply that natural selection is crucial in decreasing IAW.

The findings of IAW in White Roman geese revealed that only a few geese with slight AW of one wing or both wings during 6 to 12 weeks of age returned to NW during 10 to 14 weeks of age (data not shown), possibly because the primary wings grow completely during 6 to 12 weeks of age, whereas the secondary wings grow incompletely at the same time. Therefore, wings with a slight appearance of AW are misjudged as temporarily unfolded wings, leading to an error in observation. Moreover, Pitman et al. (2012) reported that the AW of masked boobies returned to NW at the fledging age. In this study, a few geese were observed with slight AW at 8 weeks of age, which resumed to NW at 10 weeks of age. Therefore, AW was more frequently observed in geese at 8 weeks than at 10 weeks of age, suggesting that the IAW and SSAW of a flock vary at different ages.

An optimal stocking density positively promotes animal health and performance. The effects of stocking density on feed consumption, feed conversion ratio, and carcass characteristics have been comprehensively investigated in various poultry species (Cain et al., 1984; Shanawany, 1988; Şengület al., 2000; Chang et al., 2010). Moreover, White Italian geese under HD exhibited a lower growth performance than did those under LD (4 geese $/ \mathrm{m}^{2}$ vs 2 to 3 geese $/ \mathrm{m}^{2}$; Kaszynsko et al., 1986).

Chang et al. (2010) revealed that the body weight under LD $\left(0.8\right.$ geese $\left./ \mathrm{m}^{2}\right)$ was higher than that under HD (1.6 geese $/ \mathrm{m}^{2}$ ) during winter; a similar association between body weight and three stocking densities was observed in the present study.

Growth performance in terms of feed intake, body weight gain, and body weight uniformity reduces when geese are subjected to HD or crowded conditions. Therefore, after examining only the body weight, feed consumption, and feed conversion rate under high and low temperatures, Chang et al. (2010) suggested that geese be housed and reared under a stocking density of 1.2 geese $/ \mathrm{m}^{2}$ on a slat floor. To avoid IAW and for the welfare of geese, a stocking density of $<1.2$ geese $/ \mathrm{m}^{2}$ is recommended, although the exact optimal space for rearing a goose has not been determined yet, thus necessitating future studies.

\section{CONCLUSION}

To improve production efficiency and reduce production cost, geese with a high body weight and a fast growth rate have been selected and subjected to limited space or a crowded environment. These factors may increase the risk of AW. This study showed that the stocking density applied in commercial goose farming and in our experiments did not completely avoid IAW, although a satisfactory growth performance was observed. Additional studies are required to elucidate the optimal stocking density for reducing IAW to an acceptable level in commercial goose farming.

\section{CONFLICT OF INTEREST}

We certify that there is no conflict of interest with any financial organization regarding the material discussed in the manuscript.

\section{ACKNOWLEDGMENTS}

We thank our colleagues at Changhua Animal Propagation Station, Livestock Research Institute of Council of Agriculture, Taiwan for feeding and managing the geese.

\section{REFERENCES}

Cain, J. R., J. M. Weber, T. A. Lockamy, and C. R. Crager. 1984. Grower diets and bird density effects on growth and cannibalism in ring necked pheasants. Poult. Sci. 63:450-457.

Chang, Y. C., C. M. Wang, P. C. Nien, C. L. Hu, and Y. S. Jea. 2010. The effects of stocking density on the growth performance of growing geese raised in a slat floor house. J. Taiwan Livest. Res. 43:51-58.

Francis, D. W., R. H. Roberson, and L. A. Holland. 1967. Observations on "Angel wing" in White Chinese geese. Poult. Sci. 46:768-769.

Grow, O. 1972. Slipped or twisted wing, in: modern waterfowl management and breeding guide. American Bantam Association, Three Rivers, MI, USA. pp. 171.

Kaszynsko, J., K. Bielinska, and K. Bielinski. 1986. Effect of stocking rate on geese rearing and fattening results. Rocz. Nauk. Zoot. 13:273-281.

Kear J. 1973. Notes on the nutrition of young waterfowl, with special reference to slipped-wing. Int. Zoo Yearb. 13:97-100.

Kreeger, T. J. and M. M. Walser. 1984. Carpometacarpal deformity in giant Canada geese (Branta canadensis maxima delacour). J. Wild. Dis. 20:245-248.

Kuiken, T., F. A. Leighton, G. Wobeser, and B. Wagner. 1999. Causes of morbidity and mortality and their effect on reproductive success in double-crested cormorants from Saskatchewan. J. Wild. Dis. 35:331-346.

Lee, C. H. 2004. Investigating the Causes Affecting the Incidence of Angel Wings in Geese. Master thesis, University of Chung 
Hsing, Taichung, Taiwan. pp. 6-8.

Lin, M. J., S. C. Chang, S. R. Lee, Y. S. Jea, C. F. Chen, Y. K. Fan, and Y. S. Cheng. 2010. Selection for heavy White Roman goose line. J. Chin. Soc. Anim. Sci. 39:253-260.

Lin, M. J., S. C. Chang, Y. S. Jea, Y. S. Cheng, and Y. K. Fan. 2012. Effects of line and nutrition concentration of diet on occurrence of angel wing in White Roman geese. J. Chin. Soc. Anim. Sci. 41:187-196.

Mildred, M. and W. D. Holderread. 1981. Slipped wing. In: The Book of Geese - A Complete Guide to Raising the Home Flock, pp. 140 Oregon, Hew House Publications, Corvallis, OR, USA.

NRC (National Research Council). 1994. Nutrient Requirements of Poultry. $9^{\text {th }}$ rev. edn, National Academy Press, Washington, DC, USA.
Pitman, R. L., T. B. Lisa, and A. B. Charles. 2012. Incidence of wing deformities ('Angel Wing') among Masked Boobies at Clipperton Island: life history consequences and insight into etiology. Wilson J. Ornithol. 124:597-602.

Rath, N. C., G. R. Huff, W. E. Huff, and J. M. Balog. 2000. Factors regulating bone maturity and strength in poultry. Poult. Sci. 79:1024-1032.

SAS Institute. 2004. SAS/STAT Guide for Personal Computers. Version 9.0.1. SAS Inst. Inc., Cary, NC, USA.

Şengül, T., A. Yildiz, and Y. Konca. 2000. Effect of stocking density on the growth performance and carcass characteristics in bronze Turkey. J. Poult. Res. 2:33-39.

Shanawany, M. M. 1988. Broiler performance under high stocking densities. Br. Poult. Sci. 29:43-52.

Wang, S. D., K. C. Wu, T. S. Chiou, Z. T. Chen, and L. T. Yeh. 1996. The investigation of breeder geese's information in 1995. Taiwan Agric. 32:82-88. 